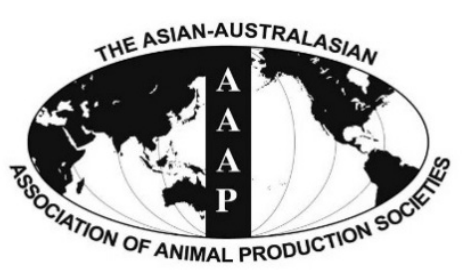

Open Access

Asian Australas. J. Anim. Sci.

Vol. 28, No. 9 : 1296-1302 September 2015

http://dx.doi.org/10.5713/ajas.15.0235

Www.ajas.info

pISSN 1011-2367 elSSN 1976-5517

\title{
Effects of Supplementing Brown Seaweed By-products in the Diet of Holstein Cows during Transition on Ruminal Fermentation, Growth Performance and Endocrine Responses
}

\author{
Z. S. Hong ${ }^{\text {a }}$, E. J. Kim ${ }^{1, \text { a }}$, Y. C. Jin ${ }^{2}$, J. S. Lee' ${ }^{2}$ Y. J. Choi ${ }^{3}$, and H. G. Lee ${ }^{2, *}$ \\ Department of Animal Science and Technology, Tianjin Agricultural University, Tianjin 300384, China
}

\begin{abstract}
This study was conducted to examine the effects of supplementing brown seaweed by-products (BSB) in the diet of ruminants on ruminal fermentation characteristics, growth performance, endocrine response, and milk production in Holstein cows. In Experiment 1 , the effects of different levels $(0 \%, 2 \%$, and $4 \%$ of basal diet as Control, $2 \% \mathrm{BSB}, 4 \% \mathrm{BSB}$, respectively) of BSB were evaluated at $3,6,9,12$, and $24 \mathrm{~h}$ in vitro batch culture rumen fermentation. The $\mathrm{pH}$ tended to be higher for the higher level of BSB supplementation, with the $\mathrm{pH}$ at $12 \mathrm{~h}$ being significantly higher $(\mathrm{p}<0.05)$ than that of the control. The concentration of ammonia nitrogen was lower at $3,9,12$, and $24 \mathrm{~h}$ incubation $(\mathrm{p}<0.05)$ compared with the control, and tended to be low at other incubation times. Volatile fatty acid concentration appeared to be minimally changed while lower values were observed with $4 \%$ BSB treatment at $24 \mathrm{~h}$ ( $\mathrm{p}<0.05$ ). In Experiment 2, effects of levels $(0 \%, 2 \%$, and $4 \%)$ of BSB on growth performance, endocrine responses and milk production were studied with Holstein dairy cows during transition. Dry matter intake, daily gain and feed efficiency were not affected by BSB supplementation. The concentration of plasma estrogen for the control, $2 \%$ BSB and $4 \%$ BSB after three months of pregnancy were $55.7,94.1$, and $72.3 \mathrm{pg} / \mathrm{mL}$, respectively $(\mathrm{p}=0.08)$. Although the differences of progesterone levels between BSB treatments and the control were minimal, the concentration in $4 \%$ BSB treatment increased to $157.7 \%$ compared with the initial level of the study. Triiodothyronine and thyroxine levels were also higher after both three months and eight months of pregnancy than the initial level at the beginning of the study. In addition, BSB treatments during one month after delivery did not affect daily milk yield and composition. In conclusion, the present results indicate that supplementation of BSB did not compromise ruminal fermentation, and animal performance at lower levels and hence may have potential to be used as a safe feed ingredient in dairy cows. (Key Words: Brown Seaweed By-products, Growth Performance, Fermentation, Blood metabolites, Holstein Cows)
\end{abstract}

\section{INTRODUCTION}

Brown seaweed (Undaria pinnatifida) is rich in a polysaccharide of alginic acid which has been demonstrated

\footnotetext{
* Corresponding Author: H. G. Lee. Tel: +82-2-450-4387, Fax: +82-2-3436-0106, E-mail: hglee66@konkuk.ac.kr

${ }^{1}$ Department of Animal Science, Kyungpook National University, Sangju 742-711, Korea.

2 Department of Animal Science and Technology, Konkuk University, Seoul 140-701, Korea.

${ }^{3}$ Laboratory of Animal Cell Biotechnology, Department of Agricultural Biotechnology, Seoul National University, Seoul 151-742, Korea.

${ }^{a}$ These authors contributed equally to this study.

Submitted Mar. 18, 2015; Revised Apr. 23, 2015; Accepted May 26, 2015
}

to suppress cholesterol absorption, and discharge heavy metals as well as act to prevent artery hardening (Kimura et al., 1996; Amano et al., 2005; Yoon et al., 2008). Acid water-soluble polysaccharide of fucoidan in the brown seaweed has shown effects of anti-coagulation of blood (Nishino et al., 2000), anti-tumor, anti-cancer activity (Haroun-Bouhedja et al., 2002; Maruyama et al., 2003) and anti-oxidation (Allen et al., 2001) and these benefits in part result from increasing thrombin, Factor Xa, urokinase-type plasminogen activator and tissue plasminogen activator. In addition, alginate oligomer, which is a degradation product of alginates by an enzyme in brown seaweed, in a large quantities can directly and indirectly influence the activation of immune system in the body by increasing cytokine secretion (Iwamoto et al., 2003) and improving the 
bioavailability of zinc (Yonekura and Suzuki, 2003). Brown seaweed also contains a large amount of minerals with higher contents of iodine (I) and calcium (Ca) compared with other foods (Kaufmann et al., 1998).

Brown seaweed is in the diets of humans in Asian countries including Korea, Japan and some part of China, but because only the leaves of brown seaweed is commercially available a vast amount of stems and roots remain as seaweed by-products. On the other hand, many countries with coastline often have problems with seaweed, and there is a potential to use brown seaweed and its byproducts for other purposes such as animal diets or a fertilizer. Studies to use seaweeds as a feed were attempted earlier (Kaufmann et al., 1998; Fleurence, 1999; Bach et al., 2008; Holdt and Kraan, 2011). However, studies with dairy cows are limited to only the effects of supplementing brown seaweed by-products (BSB) on in vitro fermentation characteristics, milk production and milk composition with little information being available for its effects on growth, reproduction and milk production after parturition in dairy cows. In the present study therefore, the effects of BSB on fermentation characteristics in the rumen have been examined in vitro, and then the influence of adding BSB in the diet of Holstein dairy cattle on animal performance, endocrine responses, and milk production were investigated.

\section{MATERIALS AND METHODS}

The present study consisted of two experiments. In Experiment 1, the effect of different levels of BSB on fermentation characteristics in vitro was examined, while in Experiment 2 the influence of supplementing BSB on growth, endocrine responses, and milk production of Holstein cow was studied.

Experiment 1: Effect of different levels of BSB on fermentation characteristics in the rumen in vitro

Experimental design and diets: The study involved an examination of fermentation characteristics in the rumen using in vitro batch culture in triplicate with supplementation of $\mathrm{BSB}$ at various levels, namely $0 \%$ (control), $2 \%$ (2\% BSB), and 4\% (4\% BSB) of dry matter, having replaced hay in the basal diets. Basal diets consisted of a mixture with commercial concentrates and hay approximately in the ratio of 35:65 as incubation substrates (Tables 1 and 2).

Preparation of rumen inoculum and incubation procedure: Rumen inoculum used was obtained from a Holstein cow equipped with a permanent ruminal cannula. Once being taken, rumen contents were transferred to a laboratory using a thermos bottle kept at $39^{\circ} \mathrm{C}$, immediately after which the rumen content was filtered with four layers cheesecloth to remove feed particles, and stored in a
Table 1. Chemical composition of feeds used in Experiments 1 and 2 ( $\%$ of dry matter unless otherwise stated)

\begin{tabular}{lccc}
\hline \multirow{2}{*}{ Item } & \multicolumn{3}{c}{ Diets } \\
\cline { 2 - 4 } & Concentrate & Tall fescue & BSB \\
\hline Crude protein & 13.50 & 14.21 & 8.37 \\
Ether extract & 2.00 & 3.47 & 0.87 \\
Crude fiber & 10.00 & 26.16 & 11.53 \\
Crude ash & 15.00 & 6.24 & 35.84 \\
$\mathrm{Ca}$ & 0.90 & 0.14 & 1.05 \\
$\mathrm{P}(\mathrm{mg} / 100 \mathrm{~g})$ & 0.50 & 0.02 & 0.24 \\
I (mg/100 g) & - & - & 7.8 \\
Total digestible nutrients & 68.00 & 51.00 & 43.20 \\
\hline
\end{tabular}

BSB, brown seaweed by-products.

constant temperature bath maintained at $39^{\circ} \mathrm{C}$. The filtered rumen fluid was mixed with McDougal's buffer (McDougall, 1948) bubbled with $\mathrm{CO}_{2}$ in 1:1 ratio, and used as a rumen inoculum. First, $0.25 \mathrm{~g}$ of substrate was placed in a $120 \mathrm{~mL}$ serum bottle, into which $25 \mathrm{~mL}$ of rumen inoculum was added under anaerobic conditions. The bottles were plugged with a butyl-rubber stopper and aluminum cap, and were incubated in a shaking incubator (SI-600R, Lab. Companion, Seoul, Korea) maintained at $39^{\circ} \mathrm{C}, 120 \mathrm{rpm}$, where the incubation times were $0,3,6,9$, 12 , and $24 \mathrm{~h}$. After completion of each incubation time, the $\mathrm{pH}$ was measured immediately using a $\mathrm{pH}$ meter (inoLab $\mathrm{pH}$ Level 1, Weilheim, Germany), and supernatant was sampled after centrifugation at 3,000 rpm for $15 \mathrm{~min}$, and stored at $-20^{\circ} \mathrm{C}$ for the analyses of ammonia nitrogen $\left(\mathrm{NH}_{3}-\right.$ $\mathrm{N}$ ) and volatile fatty acids (VFA). For VFA analysis, $4 \mathrm{~mL}$ of supernatant was added to $1 \mathrm{~mL}$ of $25 \% \mathrm{HPO}_{3}$ and stored at $-72^{\circ} \mathrm{C}$.

Sample analysis: Dry matter (DM), crude protein, ether extracts, organic matter, $\mathrm{Ca}$ and phosphorus of basal diets

Table 2. Ingredient and chemical composition of experimental diets used in Experiments 1 and 2 (\% of dry matter unless otherwise stated)

\begin{tabular}{lccc}
\hline Item & Control & 2\% BSB & $4 \%$ BSB \\
\hline Ingredient & & & \\
Concentrate & 36.49 & 37.17 & 35.09 \\
Tall fescue hay & 63.51 & 60.93 & 61.47 \\
BSB & 0 & 1.90 & 3.44 \\
Total & 100.0 & 100.0 & 100.0 \\
Chemical composition & & & \\
$\quad$ Dry matter & 89.57 & 89.50 & 89.52 \\
Crude protein & 13.95 & 13.84 & 13.76 \\
Ether extract & 2.89 & 2.83 & 2.82 \\
Neutral detergent fiber & 52.14 & 51.46 & 51.76 \\
Acid detergent fiber & 27.53 & 27.07 & 27.34 \\
Ca & 0.45 & 0.47 & 0.47 \\
P & 0.33 & 0.33 & 0.33 \\
I (ppm) & - & 1.35 & 2.70 \\
Total digestible nutrients & 57.15 & 57.12 & 56.64 \\
\hline
\end{tabular}

BSB, brown seaweed by-products. 
and BSB used were analyzed according to the method of AOAC (1995), and acid detergent fiber and neutral detergent fiber were analyzed according to the method of Van Soest et al. (1991). Analysis of ammonia-N was determined by using a spectrophotometer (Optizen 1142H, MECASYS Co., Ltd, Daejeon, Korea) after color fixation in the same quantities for phenol and alkali according to Chaney and Marbach (1962). An analysis of VFA was made with gas chromatography (VARIAN CP-3800, Varian Inc., Walnut Creek, CA, USA) according to the method by Erwin et al (1961) with a fused silica capillary column (30 $\mathrm{m} \times 0.32$ $\mathrm{mm}, \quad 0.5 \mu \mathrm{m}$ film thickness, HP Innowax, Agilent Technologies Inc., Santa Clara, CA, USA) equipped with flame ionization detector.

Experiment 2: Effect of supplementing BSB on growth, endocrine status, and milk production of Holstein dairy cows

Experimental design and animals: Initially, twenty-one Holstein heifers (average body weight $419 \mathrm{~kg}$ ) were randomly divided into 3 groups, consisting of control, $2 \%$ (2\% BSB) and 4\% (4\% BSB) supplementation of BSB by replacing a relatively similar portion of tall fescue based on nutritional requirements (Tables 1 and 2), and the experiment was conducted for 12 months at the research farm of Seoul National University, Korea. All experimental procedures were in accordance with the "Guidelines for Care and Use of Experimental Animals of Konkuk University".

Feeding management: All heifers were offered feed based on their nutritional requirements with the target body weight gain at $0.7 \mathrm{~kg} / \mathrm{d}$, depending on their body weights and weight gains as shown by National Research Council (2001). Concentrates mixed with BSB were offered twice a day at 8:30 AM and 16:00 PM, and tall fescue was fed at $65 \%$ of DM intake with water and mineral blocks. Chemical composition of BSB was same as the one used in Experiment 1 (Tables 1 and 2). Body weight was measured at 9:00 AM at intervals of 2 months and at the end of the study. Animal performance in terms of daily gain and feed intake was measured for 9 months. Two months after beginning the experiment, artificial insemination of heifers was implemented by a specialized inseminator after confirmation of estrus. Most heifers gave birth to calves, and milk samples were collected (see below for the sampling procedure). However, 2 animals from the control and 1 animal from $2 \%$ BSB and 4\% BSB fail to give a birth and hence were omitted from blood and milk sampling.

Sample collection and analysis: Ten-mL of blood was collected from the jugular veins in a heparin-treated vacuum tube (BD Vacutainer Systems Preanalytical Solutions, Becton, Dickinson and Company, Franklin Lakes, NJ, USA) at 9:00 AM before the start of the experiment, on 120th day and 240th day of pregnancy. After collection, the plasma was separated by centrifugation $\left(4^{\circ} \mathrm{C}, 3,000 \mathrm{rpm}, 15 \mathrm{~min}\right)$, and stored at $-70^{\circ} \mathrm{C}$ until further analysis. Milk production was recorded daily by automatic recording with ALPRO SYSTEM (Alfa-Laval Agri., Peterborough, Ontario, Canada), and 30 days after parturition the milk was analyzed for milk protein, milk fat, lactose and solid-not-fat (SNF) using Milkoscan-133B (Foss, Hilleroed, Denmark), and the number of somatic cells was determined by using Fossomatic-300 (Foss).

Analysis of total estrogen, progesterone, triiodothyronine (T3) and thyroxine (T4) in blood was as follows; Total estrogen was measured by radioimmunoassay (RIA) method using DA Total Estrogen kit (ICN Biomedicals, Irvine, CA, USA), and progesterone measured using CoAT-A-OUNT Progesterone kit (Diagnostic Products Corporation, Los Angeles, CA, USA). T3 and T4 were determined by RIA method using RIA-mat-T3 and RIA-mat-T4 kits (Byk-Sangtec Diagnostica, Dietzenbach, Germany).

\section{Calculation and statistical analysis}

All the results for Experiments 1 and 2 were subjected to analysis of variance with the level of BSB as the main effect using SAS version 8.1 (SAS Institute Inc., Cary, NC, USA) (SAS Institute Inc., 2000). Mean values for each treatment were further tested by Duncan's multiple range test, and the significance was declared when $p<0.05$.

\section{RESULTS AND DISCUSSION}

\section{Experiment 1: Effect of different levels of BSB on fermentation characteristics in the rumen in vitro}

The $\mathrm{pH}$ in vitro changed very little, ranging from 6.20 to

Table 3. Effects of dietary BSB supplementation on in vitro $\mathrm{pH}$ and ammonia nitrogen $\left(\mathrm{NH}_{3}-\mathrm{N}\right)$ concentration in Experiment 1

\begin{tabular}{lccccc}
\hline \multirow{2}{*}{$\begin{array}{l}\text { Incubation } \\
\text { time }(\mathrm{h})\end{array}$} & \multicolumn{3}{c}{ Treatments $^{1}$} & SEM & p-value \\
\cline { 2 - 4 } $\mathrm{pH}$ & Control & $2 \% \mathrm{BSB}$ & $4 \% \mathrm{BSB}$ & & \\
3 & 6.62 & 6.60 & 6.63 & 0.009 & 0.546 \\
6 & 6.51 & 6.51 & 6.53 & 0.008 & 0.535 \\
9 & 6.39 & 6.37 & 6.39 & 0.007 & 0.460 \\
12 & $6.26^{\mathrm{b}}$ & $6.30^{\mathrm{a}}$ & $6.30^{\mathrm{a}}$ & 0.005 & 0.028 \\
24 & 6.22 & 6.20 & 6.22 & 0.014 & 0.747 \\
$\mathrm{NH}_{3}-\mathrm{N}(\mathrm{mg} / \mathrm{dL})$ & & & & & \\
3 & $7.66^{\mathrm{a}}$ & $6.44^{\mathrm{a}, \mathrm{b}}$ & $5.05^{\mathrm{b}}$ & 0.368 & 0.072 \\
6 & 4.94 & $4.44^{\mathrm{a}}$ & 4.66 & 0.241 & 0.711 \\
9 & $6.74^{\mathrm{a}}$ & $6.98^{\mathrm{a}}$ & $3.44^{\mathrm{b}}$ & 0.497 & 0.047 \\
12 & $8.00^{\mathrm{a}}$ & $6.71^{\mathrm{a}, \mathrm{b}}$ & $4.74^{\mathrm{b}}$ & 0.485 & 0.085 \\
24 & $18.10^{\mathrm{a}}$ & $14.03^{\mathrm{b}}$ & $10.43^{\mathrm{c}}$ & 0.570 & 0.005 \\
\hline
\end{tabular}

BSB, brown seaweed by-products; SEM, standard error of the mean. ${ }^{1}$ All values represent the mean of triplicates.

a,b,c Means in the same row with different superscripts differ $(\mathrm{p}<0.05)$. 
6.63 when BSB was supplemented at different levels (Table 3). The $\mathrm{pH}$ above 6.00 at $24 \mathrm{~h}$ of incubation in all treatments indicates replacing tall fescue with BSB does not cause any unfavorable fermentative environment for microorganisms. In the case of ammonia- $\mathrm{N}$ concentrations, supplementation of BSB at $4 \%$ showed a lower $(\mathrm{p}<0.05)$ ammonia-N at 3, 9, 12, and $24 \mathrm{~h}$ of incubation as compared with the control.

Ammonia-N values above $5 \mathrm{mg} / \mathrm{dL}$ in the rumen are known to be optimal for microbial growth (Satter and Slyter, 1974), although there are large discrepancies among studies (i.e., $1.4 \mathrm{mg} / \mathrm{Dl}$ [Schaefer et al., 1980] to $19.4 \mathrm{mg} / \mathrm{dL}$ [Mehrez et al., 1977]). The large quantities polysaccharides present in brown seaweed exist in structural carbohydrates including alginic acid, fucoidan and laminaran, and consists of heteropolysaccharides such as D-mannuronic acid and its isomer of L-guluronic acid, which account for most of the cell walls of Phaeophyceae, including brown seaweed
(Beresford et al., 2000; Klinkenberg et al., 2001). These polysaccharides can be easily degraded by the rumen microbes and act as an energy for the microbes in the rumen (Greenwood et al., 1983; Beresford et al., 1999). Hence, reduction in ammonia-N with supplemented BSB is likely to occur due to synchronization between energy and $\mathrm{N}$ for the growth of rumen microorganisms. Concentrations of VFA were not different except for $24 \mathrm{~h}$ of incubation where total VFA concentration was lower $(\mathrm{p}<0.05)$ when $4 \%$ BSB was supplemented (Table 4). It is unclear why VFA concentration with $4 \%$ BSB diet at $24 \mathrm{~h}$ was lower than that in the other dietary treatments. One might speculate that DMD (dry matter degradability) is lower with $4 \% \mathrm{BSB}$; however, it is difficult to conclude this as we did not obtain results on DMD.

From the results of the in vitro study, the BSB supplementation did not change ruminal $\mathrm{pH}$ with little variation at high level of concentrate in the diets, and may

Table 4. Effects of dietary BSB supplementation on in vitro volatile fatty acids concentration in Experiment 1

\begin{tabular}{|c|c|c|c|c|c|}
\hline \multirow{2}{*}{ Incubation time (h) } & \multicolumn{3}{|c|}{ Treatments $^{1}$} & \multirow{2}{*}{ SEM } & \multirow{2}{*}{ p-value } \\
\hline & Control & $2 \% \mathrm{BSB}$ & $4 \% \mathrm{BSB}$ & & \\
\hline \multicolumn{6}{|l|}{ Acetate $(\mathrm{mM})$} \\
\hline 3 & 45.47 & 48.30 & 46.02 & 1.434 & 0.8253 \\
\hline 6 & 53.29 & 52.39 & 55.48 & 0.972 & 0.5745 \\
\hline 9 & 62.51 & 56.41 & 52.96 & 1.884 & 0.0697 \\
\hline 12 & 62.58 & 60.98 & 62.97 & 1.607 & 0.8789 \\
\hline 24 & $71.47^{\mathrm{a}}$ & $77.47^{\mathrm{a}}$ & $62.40^{\mathrm{b}}$ & 2.408 & 0.0057 \\
\hline \multicolumn{6}{|l|}{ Propionate (mM) } \\
\hline 3 & 11.78 & 12.78 & 12.75 & 0.473 & 0.7730 \\
\hline 6 & 14.52 & 14.64 & 16.20 & 0.430 & 0.3446 \\
\hline 9 & 17.69 & 15.21 & 15.58 & 0.536 & 0.0738 \\
\hline 12 & 17.95 & 17.64 & 19.47 & 0.646 & 0.4907 \\
\hline 24 & $20.70^{\mathrm{a}, \mathrm{b}}$ & $23.69^{\mathrm{a}}$ & $19.15^{\mathrm{b}}$ & 0.797 & 0.0357 \\
\hline \multicolumn{6}{|l|}{ Butyrate (mM) } \\
\hline 3 & 5.99 & 6.59 & 6.14 & 0.326 & 0.8504 \\
\hline 6 & 7.57 & 7.16 & 7.90 & 0.210 & 0.5047 \\
\hline 9 & 9.60 & 8.09 & 7.26 & 0.483 & 0.1133 \\
\hline 12 & 9.65 & 9.09 & 9.25 & 0.407 & 0.8683 \\
\hline 24 & $11.45^{\mathrm{a}}$ & $12.06^{\mathrm{a}}$ & $8.97^{\mathrm{b}}$ & 0.551 & 0.0116 \\
\hline \multicolumn{6}{|l|}{ Valerate $(\mathrm{mM})$} \\
\hline 3 & 0.69 & 0.74 & 0.64 & 0.046 & 0.7955 \\
\hline 6 & 0.83 & 0.76 & 0.81 & 0.022 & 0.4254 \\
\hline 9 & 1.05 & 0.90 & 0.72 & 0.065 & 0.0827 \\
\hline 12 & 1.06 & 1.00 & 0.97 & 0.050 & 0.7851 \\
\hline 24 & $1.43^{\mathrm{a}}$ & $1.40^{\mathrm{a}}$ & $1.08^{\mathrm{b}}$ & 0.072 & 0.0043 \\
\hline \multicolumn{6}{|c|}{ Total volatile fatty acids (mM) } \\
\hline 3 & 65.26 & 69.94 & 66.99 & 2.324 & 0.8332 \\
\hline 6 & 77.70 & 76.39 & 82.01 & 1.645 & 0.5073 \\
\hline 9 & 92.82 & 82.26 & 77.87 & 3.033 & 0.0753 \\
\hline 12 & 93.33 & 90.64 & 94.55 & 2.740 & 0.8526 \\
\hline 24 & $108.41^{\mathrm{a}}$ & $118.14^{\mathrm{a}}$ & $93.97^{\mathrm{b}}$ & 3.941 & 0.0089 \\
\hline
\end{tabular}

BSB, brown seaweed by-products; SEM, standard error of the mean.

${ }^{1}$ All values represent the mean of triplicates. ${ }^{a, b}$ Means in the same row with different superscripts $\operatorname{differ}(\mathrm{p}<0.05)$. 
Table 5. Effects of dietary BSB supplementation on growth performance for 9 months in Holstein heifers in Experiment 2

\begin{tabular}{lccccc}
\hline Item & Control & 2\% BSB & $4 \%$ BSB & SEM & p-value \\
\hline Initial body weight (kg) & 419.1 & 419.0 & 419.1 & 8.85 & 0.9997 \\
Final body weight (kg) & 612.7 & 610.3 & 611.7 & 17.46 & 0.9927 \\
Weight gain (kg) & 193.6 & 191.3 & 192.6 & 6.35 & 0.9928 \\
Daily weight gain (kg/d) & 0.70 & 0.70 & 0.70 & 0.023 & 0.9963 \\
Feed intake (kg/d) & 10.58 & 10.36 & 10.49 & - & - \\
Tall fescue & 6.78 & 6.38 & 6.45 & - & - \\
BSB & 0 & 0.18 & 0.36 & - & - \\
Concentrate & 3.80 & 3.78 & 3.58 & - & - \\
Growth efficiency (\%) & 6.62 & 6.76 & 6.68 & - & - \\
\hline
\end{tabular}

BSB, brown seaweed by-products; SEM, standard error of the mean.

show potential to improve $\mathrm{N}$ metabolism in the rumen without a particular influence on the generation of VFA for other than $24 \mathrm{~h}$ of fermentation. Thus it was not considered that supplementation of BSB in the diets of ruminants had an unfavorable influence on the fermentation characteristics in the rumen.

Experiment 2: Influence of adding BSB on growth, endocrine response, and milk production of Holstein dairy cows during transition

Animal performance: Animal performance in terms of daily gain and feed intake of Holstein cows is presented in Table 5. Daily gains with an average weight of $419 \mathrm{~kg}$ for a total of 275 days were approximately $0.7 \mathrm{~kg} / \mathrm{d}$ for all three treatments as expected, indicating that addition of BSB did not influence daily gains. Alginic acids composing cell walls of seaweeds have been reported to have characteristics of forming viscous gel so that palatability preference is lowered, accompanied by a reduction in feed intakes (Beresford et al., 2000). Franklin et al. (1999) also reported that DM intake was significantly reduced as a result of daily supplementation of seaweeds for milking cows. On the other hand, the levels of supplement in the present study are not considered to have major impact on DM intake, as similar results were observed between treatments where total DM intakes were 10.58, 10.36, and $10.49 \mathrm{~kg}$ for the control, $2 \% \mathrm{BSB}$ and $4 \% \mathrm{BSB}$, respectively. However, as this experiment was conducted with a group feeding regime and the results were presented with a mean value of all animals within a treatment, statistical analysis of the feed intake was not provided.

Endocrine responses: Influences of adding $\mathrm{BSB}$ on various hormones in blood are given in Table 6 . The pattern of estrogen before and after pregnancy indicated a normal pattern of estrogen. In terms of both estrogen and progesterone, no particular differences per stage were indicated among treatments. T3 and T4 are hormones synthesized in the thyroid glands, where I is an important precursor for the synthesis. Pattanaik et al. (2001) reported that contents of $\mathrm{T} 3$ and $\mathrm{T} 4$ in plasma had increased

Table 6. Effects of dietary BSB supplementation on endocrine response of Holstein dairy heifers in Experiment $2^{1}$

\begin{tabular}{|c|c|c|c|c|c|}
\hline Item & Control & $2 \% \mathrm{BSB}$ & $4 \% \mathrm{BSB}$ & SEM & p-value \\
\hline \multicolumn{6}{|l|}{ Before BSB offered } \\
\hline Estrogen $(\mathrm{pg} / \mathrm{mL})$ & 20.57 & 20.57 & 23.14 & 1.417 & 0.3101 \\
\hline Progesterone (ng/mL) & 3.26 & 3.26 & 1.94 & 0.438 & 0.0917 \\
\hline T3 (ng/dL) & 167.24 & 167.24 & 147.47 & 2.865 & 0.0163 \\
\hline $\mathrm{T} 4(\mu \mathrm{g} / \mathrm{dL})$ & 6.52 & 6.53 & 6.19 & 0.145 & 0.1531 \\
\hline \multicolumn{6}{|l|}{ Conception at $120 \mathrm{~d}$} \\
\hline Estrogen (pg/mL) & 55.71 & 94.14 & 72.73 & 7.314 & 0.0764 \\
\hline Progesterone $(\mathrm{ng} / \mathrm{mL})$ & 4.92 & 5.84 & 4.61 & 0.450 & 0.4479 \\
\hline T3 (ng/dL) & 159.69 & 167.71 & 153.12 & 3.695 & 0.1843 \\
\hline $\mathrm{T} 4(\mu \mathrm{g} / \mathrm{dL})$ & 5.95 & 6.25 & 5.35 & 0.235 & 0.1957 \\
\hline \multicolumn{6}{|l|}{ Conception at $240 \mathrm{~d}$} \\
\hline Estrogen (pg/mL) & 121.57 & 189.57 & 165.22 & 20.159 & 0.3871 \\
\hline Progesterone (ng/mL) & 5.53 & 5.19 & 5.00 & 0.446 & 0.8902 \\
\hline $\mathrm{T} 3(\mathrm{ng} / \mathrm{dL})^{2}$ & 160.38 & 167.29 & 156.14 & 2.419 & 0.0888 \\
\hline $\mathrm{T} 4(\mu \mathrm{g} / \mathrm{dL})^{3}$ & 5.45 & 5.95 & 5.36 & 0.212 & 0.4149 \\
\hline
\end{tabular}

BSB, brown seaweed by-products; SEM, standard error of the mean.

${ }^{1}$ Experimental animals were heifers and were conceived during the study.

${ }^{2}$ Triiodothyronine. ${ }^{3}$ Thyroxine. 
significantly compared with the control when I at the level of $0.05 \mathrm{mg}$ and $0.075 \mathrm{mg}$ per head a day was added in the basic feeds for goats. However, a pattern of increase in hormone synthesis in the thyroid glands was not exhibited per stage in the present study. In the case of T3, only a slight increase of $3.83 \%$ and $5.87 \%$ was observed when compared with the beginning of the study for a pregnancy of 120 days and 240 days, respectively.

Milk production and composition: Milk productions and milk composition 1 month after delivery of dairy cows are given in Table 7. DM intakes showed similar results among treatments with $21.05 \mathrm{~kg}, 20.88 \mathrm{~kg}, 20.52 \mathrm{~kg}$ for the control, $2 \%$ BSB, 4\% BSB, respectively. Although the concentrations of estrogen and progesterone during pregnancy period, which tended to show higher values for $2 \%$ BSB compared with other treatments, were expected to influence duct development causing differences in milk production, no differences in milk production were brought about with resultant values of $27.14 \mathrm{~kg}, 28.77 \mathrm{~kg}, 27.65 \mathrm{~kg}$ corresponding to the control, $2 \% \mathrm{BSB}$ and $4 \% \mathrm{BSB}$, respectively at 4 th week of lactation. Contents of milk protein, milk fat, lactose, SNF were shown to be similar among treatments, indicating that addition of BSB during pregnancy period did not have an influence in the lactation period. Our results are somewhat different compared with previous reports. For example, Bendary et al. (2013) reported increased milk yield when dairy cows were supplemented with the mixture of seaweed and premix, and another study also has shown a similar result, an increased milk yield in high-yielding dairy cows (Hostens et al., 2011). The discrepancy in terms of milk yield between previous studies and our results remains to be determined. It is interesting to note, however, that in the report by Kellogg et al. (2006) where they concluded from a series of studies that supplementation of commercially available brown seaweed such as Tasco (Acadian Seaplants Ltd., Dartmouth, Nova Scotia, Canada) is beneficial for milk production in large dairy cows during moderate to severe heat stress, but not with cows at first-lactation where the body size is still

Table 7. Effects of dietary BSB supplementation on DMI, milk yield and composition of Holstein dairy cows in Experiment 2

\begin{tabular}{lccccc}
\hline \multirow{2}{*}{ Item } & \multicolumn{3}{c}{ Treatments } & \multirow{2}{*}{ SEM } & p-value \\
\cline { 2 - 4 } & Control & 2\% BSB & $4 \%$ BSB & & \\
\hline Number of cows & 5 & 6 & 6 & & \\
DMI (kg/d) & 21.05 & 20.88 & 20.52 & 0.525 & 0.8752 \\
Milk yield (kg/d) & 27.14 & 28.77 & 27.65 & 0.342 & 0.7963 \\
Milk fat (\%) & 4.07 & 4.12 & 4.03 & 0.230 & 0.5364 \\
Milk protein (\%) & 3.11 & 3.06 & 3.12 & 0.158 & 0.8897 \\
Milk lactose (\%) & 4.71 & 4.81 & 4.73 & 0.112 & 0.7856 \\
Solid-not-fat (\%) & 8.27 & 8.31 & 8.32 & 0.175 & 0.9982 \\
\hline DMI
\end{tabular}

DMI, dry matter intake; BSB, brown seaweed by-products; SEM, standard error of the mean. relatively small compared with mature cows.

\section{IMPLICATIONS}

The present study examined the influence of BSB on fermentation characteristics in vitro and also on animal performance, endocrine response and milk production in Holstein dairy cows. From the results of both in vitro (Experiment 1) and in vivo studies (Experiment 2), it is concluded that addition of BSB hardly changes $\mathrm{pH}$, induces fermentation synchronization in vitro and has little influence on estrogen and progesterone, and no increase in milk production was observed up to 1 month after delivery. The results from our study may provide an insight in the use of by-products or waste materials in the diet of dairy cows from fisheries.

\section{CONFLICT OF INTEREST}

We certify that there is no conflict of interest with any financial organization regarding the material discussed in the manuscript.

\section{ACKNOWLEDGMENTS}

This research was supported by Bio-industry Technology Development Program (313002031HD020) for Ministry of Agriculture, Food and Rural Affairs, Republic of Korea.

\section{REFERENCES}

Allen, V. G., K. R. Pond, K. E. Saker, J. P. Fontenot, C. P. Bagley, R. L. Ivy, R. R. Evans, C. P. Brown, M. F. Miller, J. L. Montgomery, T. M. Dettle, and D. B. Wester. 2001. TascoFarage: III. Influence of a seaweed extract on performance, monocyte immune cell response, and carcass characteristics in feedlot-finished steers. J. Anim. Sci. 79:1032-1040.

Amano, H., M. Kakinuma, D. A. Coury, H. Ohno, and T. Hara. 2005. Effect of seaweed mixture on serum lipid level and platelet aggregation in rats. Fish. Sci. 71:1160-1166.

AOAC. 1995. Official Methods of Analysis. 16th edn. Association of Official Analytical Chemists, AOAC Inc., Washington, DC, USA.

Bach, S. J., Y. Wang, and T. A. McAllister. 2008. Effect of feeding sun-dried seaweed (Ascophyllum nodosum) on fecal shedding of Escherichia coli $\mathrm{O} 157$ : H7 by feedlot cattle and on growth performance of lambs. Anim. Feed Sci. Technol. 142:17-32.

Bendary, M. M., M. I. Bassiouni, M. F. Ali, H. M. Gaafar, and A. Sh. Shamas. 2013. Effect of premix and seaweed additives on productive performance of lactating friesian cows. Int. Res. J. Agric. Sci. Soil Sci. 3:174-181.

Beresford, N. A., R. W. Mayes, P. M. Colgrove, C. L. Barnett, L. Bryce, B. A. Dodd, and C. S. Lamb. 2000. A comparative assessment of the potential use of alginates and dietary 
calcium manipulation as countermeasures to reduce the transfer of radiostrontium to the milk of dairy animals. J. Environ. Radioact. 51:321-334.

Beresford, N. A., R. W. Mayes, P. J. MacEachern, B. A. Dodd, and C. S. Lamb. 1999. The effectiveness of alginates to reduce the transfer of radiostrontium to the milk of dairy goats. J. Environ. Radioact. 44:43-54.

Chaney, A. L. and E. P. Marbach. 1962. Modified reagents for determination of urea and ammonia. Clin. Chem. 8:130-132.

Erwin, E. S., G. J. Marco, and E. M. Emery. 1961. Volatile fatty acid analyses of blood and rumen fluid by gas chromatography. J. Dairy Sci. 44:1768-1771.

Fleurence, J. 1999. Seaweed proteins: biochemical, nutritional aspects and potential uses. Trends Food Sci. Technol. 10:25-28.

Franklin, S. T., K. R. Martin, R. J. Baer, D. J. Schingoethe, and A. R. Hippen. 1999. Dietary marine algae (Schizochytrium sp.) increases concentrations of conjugated linoleic, docosahexaenoic and transvaccenic acids in milk of dairy cows. J. Nutr. 129:2048-2054.

Greenwood, Y., C. G. Orpin, and I. W. Paterson. 1983. Digestibility of seaweeds in Orkney sheep. Proceedings of the Physiological Society, 16-18 June 1983, Cambridge Meeting: Babraham Poster Communications. J. Physiol. 343:120.

Haroun-Bouhedja, F., F. Lindenmeyer, H. Lu, C. Soria, J. Jozefonvicz, and C. Boisson-Vidal. 2002. In vitro effects of fucans on MDA-MB231 tumor cell adhesion and invasion. Anticancer Res. 22:2285-2292.

Holdt, S. L. and S. Kraan. 2011. Bioactive compounds in seaweed: functional food applications and legislation. J. Appl. Phycol. 23:543-597.

Hostens, M., V. Fievez, B. Vlaeminck, J. Buyse, J. Leroy, S. Piepers, S. De Vliegher, and G. Opsomer. 2011. The effect of marine algae in the ration of high-yielding dairy cows during transition on metabolic parameters in serum and follicular fluid around parturition. J. Dairy Sci. 94:4603-4615.

Iwamoto, Y., X. Xu, T. Tamura, T. Oda, and T. Muramatsu. 2003. Enzymatically depolymerized alginate oligomers that cause cytotoxic cytokine production in human mononuclear cells. Biosci. Biotechnol. Biochem. 67:258-263.

Kaufmann, S., G. Wolfram, F. Delange, and W. A. Rambeck. 1998. Iodine supplementation of laying hen feed: a supplementary measure to eliminate iodine deficiency in humans? $\mathrm{Z}$. Ernährungswiss. 37:288-293.

Kellogg, D. W., K. Anschutz, and J. Pennington. 2006. Report of research trial with Tasco at Rose Ark Dairy in Arkansas during summer 2005. AAES Research Series 545: Arkansas Animal Science Department Report 2006, Fayetteville, AR, USA. pp. 100-104.
Kimura, Y., K. Watanabe, and H. Okuda. 1996. Effects of soluble sodium alginate on cholesterol excretion and glucose tolerance in rats. J. Ethnopharmacol. 54:47-54.

Klinkenberg, G., K. Q. Lystad, D. W. Levine, and N. Dyrset. 2001. Cell release from alginate immobilized Lactococcus lactis ssp. lactis in chitosan and alginate coated beads. J. Dairy Sci. 84:1118-1127.

Maruyama, H., H. Tamauchi, M. Hashimoto, and T. Nakano. 2003. Antitumor activity and immune response of Mekabu fucoidan extracted from Sporophyll of Undaria pinnatifida. In Vivo 17:245-249.

McDougall, E. I. 1948. Studies on ruminant saliva: 1. The composition and output of sheep's saliva. Biochem. J. 43:99109 .

Mehrez, A. Z., E. R. Ørskov, and I. McDonald. 1977. Rates of rumen fermentation in relation to ammonia concentration. Br. J. Nutr. 38:437-443.

National Research Council. 2001. Nutrient requirements of dairy cattle. 7th revised edn. National Academy Press, Washington, DC, USA.

Nishino, T., T. Yamauchi, M. Horie, T. Nagumo, and H. Suzuki. 2000. Effects of a fucoidan on the activation of plasminogen by u-PA and t-PA. Thromb. Res. 99:623-634.

Pattanaik, A. K., S. A. Khan, V. P. Varshney, and S. P. Bedi. 2001. Effect of iodine level in mustard (Brassica juncea) cake-based concentrate supplement on nutrient utilisation and serum thyroid hormones of goats. Small Rumin. Res. 41:51-59.

SAS Institute Inc. 2000. User's Guide: Statistics, release. 8.1 version. SAS Institute Inc., Cary, NC, USA.

Satter, L. D. and L. L. Slyter. 1974. Effect of ammonia concentration on rumen microbial protein production in vitro. Br. J. Nutr. 32:199-208.

Schaefer, D. M., C. L. Davis, and M. P. Bryant. 1980. Ammonia saturation constants for predominant species of rumen bacteria. J. Dairy Sci. 63:1248-1263.

Van Soest, P. J., J. B. Robertson, and B. A. Lewis. 1991. Methods for dietary fiber, neutral detergent fiber, and nonstartch polysaccharides in relation to animal nutrition. J. Dairy Sci. 74:3583-3597.

Yonekura, L. and H. Suzuki. 2003. Some polysaccharides improve zinc bioavailability in rats fed a phytic acid-containing diet. Nutr. Res. 23:343-355.

Yoon, N. Y., H. R. Kim, H. Y. Chung, and J. S. Choi. 2008. Antihyperlipidemic effect of an edible brown algae, Ecklonia stolonifera, and its constituents on poloxamer 407-induced hyperlipidemic and cholesterol-fed rats. Arch. Pharm. Res. 31:1564-1571. 